\title{
LUIS MARÍA PASTOR: UN ECONOMISTA EN LA ESPAÑA DE ISABEL II
}

JOSÉ LUIS GARCIA RUIZ

Universidad Complutense de Madrid

\section{RESUMEN}

El propósito de este articulo es sacar a la luz la obra de Luis Maria Pastor, un economista español de mediados del siglo $\mathrm{xIX}$, que formuló teorias y propuestas de política económica que demuestran un conocimiento de la economía algo superior al que suele suponerse a los autores de ese periodo. Al hilo de la exposición de su obra, se hacen algunas consideraciones sobre la historia económica y politica de la época isabelina.

\section{ABSTRACT}

The purpose of this article is to review the works written by Luis Maria Pastor, an Spanish economist of mid-19th century, who made theories and proposals of political economy that show an knowledge of the economy above it is supposed. With the exposition of his work, some considerations about the economic and political history of the Isabel II times are made.

\section{INTRODUCCION *}

En el prólogo a la reimpresión de Elementos de la ciencia de la Hacienda (1961 [1825]), obra capital del liberal José Canga Argüelles, Fabián Estapé hablo de la existencia de un largo paréntesis en el desarrollo del pensamiento económico español entre la desaparición de Canga Argüelles (fallecido en 1843) y Flórez Estrada (fallecido en 1853) y la recuperación iniciada por Antonio Flores de Lemus en las primeras décadas del siglo xx. Pues bien, hoy día, más de treinta años después, seguimos careciendo de estudios monográficos

* Quiero dar las gracias a Gabriel Tortella, Carlos Rodriguez Braun, Tomás Martinez Vara y dos evaluadores anonimos por las útiles recomendaciones que sobre este trabajo me han formulado. Naturalmente, las conclusiones y los posibles errores son exclusivamente mios. 
sobre muchos de los economistas que desarrollaron su actividad en ese periodo '. Este desinterés puede justificar el juicio de Estapé, pero sin duda propicia que desconozcamos la influencia de los economistas en una etapa crucial de la evolución económica de España. En mi opinión, aunque se trate a priori de economistas menores, sin aportaciones novedosas o trascendentales, el análisis detenido de sus obras puede darnos algunas sorpresas y, en cualquier caso, nos permitirá entender cómo el pensamiento económico español pasó de seguir fielmente a Adam Smith, en la etapa previa a Isabel II, a situarse en las corrientes más «pragmáticas» de Flores de Lemus y sus discipulos. En este sentido, pretenderé demostrar en las páginas siguientes que la obra del economista Luis Maria Pastor (1804-1872) no sólo tiene interés por sí misma, sino que arroja luz sobre algunos puntos oscuros en la interpretación de la época isabelina. Con frecuencia se olvida que Pastor fue considerado en su momento el «jefe» de los economistas españoles, entendiendo por tales a los seguidores de la corriente ortodoxa liberal 2.

\section{ACOTACIONES BIOGRÁFICAS DE LUIS MARÎA PASTOR}

Luis Maria Pastor y Rodriguez nació en Barcelona, el 26 de abril de 1804 , en el seno de una familia modesta ${ }^{3}$. Estudió Derecho, y ejerció la abogacía en Madrid, Buitrago y Brihuega, a donde tuvo que trasladarse para ayudar a su familia, oriunda de esa ciudad, cuando murió su padre. Alli se casó, y luego volvió a Madrid, donde destacó profesionalmente hasta el punto de hacer una pequeña fortuna. Al parecer, le introdujo en la alta sociedad madrileña el financiero catalán Gaspar Remisa ${ }^{4}$, a quien prestó sus servicios profesionales. Asi, fue uno de los propulsores del Banco de Isabel II y, aunque no fue elegido director del mismo, terminó ocupando la vacante en el Consejo que dejó José Salamanca al ser nombrado ministro de Hacienda. Incluso el último acta del banco, de fecha 15 de octubre de 1849, está firmada por Pastor'. Sus con-

1 Las pocas excepciones que existen se mencionan en Anes (1988). Una aportación reciente es Cabrillo (1991).

2 Asi lo denomina, por ejemplo, Bravo Murillo (1865), p. 220.

3 Los datos biográficos que se exponen están basados, principalmente, en la nota necrologica que Gabriel Rodriguez, confundador de El Economista, escribio en Rodriguez (1873). Además, se ha consultado la voz aLuis Maria Pastor» en el Diccionario Enciclopedico de Espasa Calpe y en el Diccionario biográfico (tomo 4) de la Enciclopedia de Historia de España que ha dirigido Miguel Artola y publicado Alianza Editorial en 1991.

+ Vease Güell y Ferrer (1861), p. 40.

' Zumalacarregui (1952), pp. 27, 32.34 y 255. 
tactos con Salamanca no acabaron ahí, pues también fue miembro de la Junta de Gobierno del ferrocarril Madrid-Aranjuez ${ }^{\circ}$. Por ello, con cierta exageración, un autor ha llegado a señalar que Luis María Pastor fue un «gran amigo del futuro marqués» ${ }^{7}$. En realidad, da la impresión que Pastor estuvo vinculado a esos negocios por su trabajo profesional como abogado y siguiendo a su mentor, el marqués de Remisa.

En política se inició como periodista y en 1839 colaboró en la fundación de una asociación para la mejora de las cárceles. Más tarde buscó un lugar entre la fracción puritana del Partido Moderado. En 1847 fue elegido diputado por primera vez, y se le nombró director general de la Deuda Pública. Desde ese cargo, se opuso a los ataques que recibía la Bolsa madrileña, acusada de favorecer con la especulación la crisis económica del momento. En opinión de Pastor, las verdaderas causas se encontraban en la mala política económica seguida 8 .

Su primera obra de interés apareció en 1850, llevando por título Filosofía del crédito, y puso de manifiesto sus dotes como analista aventajado en las cuestiones relacionadas con el sector público. Quizá ésta fuera la única razón por la que fue elegido ministro de Hacienda durante el gobierno del general Lersundi (14 de abril-18 de septiembre de 1853), aunque sólo estuvo tres meses pues vino a sustituir a su amigo Bermúdez de Castro que dimitió dos meses después de haberse formado el equipo ministerial. La difícil coyuntura que le tocó vivir y el hecho de que el gobierno de Lersundi pretendiera ser un gabinete de conciliación nacional impidieron a Pastor poner en práctica sus ideas reformadoras. Él mismo reconoció «la absoluta imposibilidad de emprender [en aquel momento] ninguna clase de reformas trascendentales e importantes en Hacienda» ${ }^{9}$. Del siguiente modo, resumió Pastor su labor:

Procuré el arreglo de la deuda flotante; rebajé el tipo de los intereses; organicé [...] la administración; preparé trabajos de estudio [...]; formulé interrogatorios [...]; y si el resultado de los antecedentes que procuraba reunir me hubiese convencido de la posibilidad de reforma, habría propuesto la supresión de las puertas, de los consumos y de los portazgos, supliendo su importe con una contribucion general, fundada en mis principios, y con una reforma del papel sellado, basada sobre una escala progresiva desde 50 céntimos hasta 10.000 reales,

\footnotetext{
* Torrente Fortuño (1969), pp. 135-136.

Torrente Fortuño (1969), p. 103. Otras biografias de Salamanca, la del conde de Romanones o la de Florentino Hernandez. Girbal, practicamente ni mencionan a Luis Maria Pastor.

` Véase Pastor (1848), pp. 33 y ss. Pastor jugó a la Bolsa en la década de 1840, pero, como señala Torrente Fortuño (1969. p. 58), en esa época «todo el mundo jugaba a la Bolsa».

"Pastor (1856), vol. I, p. XXXVI.
} 
para hacer menos injusta y vejatoria, y más proporcional al mismo tiempo, esta odiosa contribución ${ }^{10}$.

Durante su permanencia en el gobierno también se aprobó el decreto del 7 de agosto de 1853, que justificó las irregularidades cometidas con anterioridad en la adjudicación de los ferrocarriles, por la «carencia de una legislación completa y uniforme» y por el «deseo, quizás inmoderado, de dotar al país de un medio de comunicación que con tanta rapidez venia propagándose en todas las naciones civilizadas», y procedió a renovar todas las concesiones ya realizadas proponiendo que las sucesivas se ajustasen estrictamente a los términos de la ley de $1850^{\prime \prime}$. Esta postura abstencionista fue criticada y provocó la salida de Claudio Moyano del gobierno, pero los verdaderos escándalos ferroviarios se producirian al dimitir Lersundi y formar gobierno el conde de San Luis. Este gobierno compartiria con el anterior su último ministro de Fomento, Esteban Collantes, pero Luis Maria Pastor se mantuvo al margen.

También tuvo ocasión, en el breve espacio de tiempo que fue ministro, de tener un pequeño enfrentamiento con el gobernador del Banco de España, el conservador Ramón Santillán. Como explica el propio Santillán, el arreglo de la deuda flotante, que consistio en convertirla en billetes del Tesoro con vencimientos a corto plazo, colocaba al Banco de España en una difícil situación como pagador. Además, Pastor extendió por provincias las operaciones de la Caja General de Depósitos que habia creado Bravo Murillo ${ }^{12}$. Conociendo las ideas de Pastor sobre la libertad bancaria, que no compartía Santillán, y su preocupación por desvelar las exigencias de la deuda pública no nos sorprende el carácter de esta divergencia. En realidad, era continuación de la que Santillán habia mantenido antes con Bravo Murillo.

Tras la Vicalvarada (1854), Pastor volvió a ser director de la Deuda Pública, por poco tiempo, en 1856. Es entonces cuando publica La ciencia de la contribución. En 1858 aparece la segunda edición de Filosofia del crédito. En ese mismo año, Pastor se aparta definitivamente del sistema político isabelino. A decir de su biógrafo, Gabriel Rodriguez, es el momento en que rompe «los débiles lazos con que las circunstancias del momento, más bien que las convicciones políticas», le habían unido a los antiguos partidos ${ }^{13}$. En el opúsculo La política que expira y la política que nace (1861) anunciará el carácter inevitable de

11) Ibidem, p. XXXVII.

11 Artola (1978), p. 346.

12 Santillan (1982 [1865]), pp. 43 y 47-49. Véase tambien el prólogo de Pedro Tedde a esta edicion.

13 Rodriguez (1873), p. 203. 
la revolución que se producirá siete años después. En 1859 contribuye a fundar la Asociación para la Reforma de los Aranceles de Aduanas ${ }^{14}$, y asiste con regularidad a las reuniones de la Sociedad Libre de Economía Política, promovida en 1857 por Figuerola, Colmeiro y Rodriguez, asi como a las de tres importantes foros liberales madrileños: el Ateneo, la Bolsa y el Circulo de la Unión Mercantil. En 1860 es invitado a un congreso internacional de economia en Lausana ${ }^{15}$, y en 1865 funda una sociedad para abolir la esclavitud en el mundo. También en este periodo publica tres obras: Historia de la Deuda Pública de España (1863), La libertad de bancos y cola del de España (1865) y Lecciones de Economia Política (1868).

Tras la revolución de 1868 , Pastor se encuentra viejo y enfermo pero no duda en aceptar cargos como miembro asesor de numerosas comisiones y juntas, entre ellas, la encargada de redactar un nuevo Código de Comercio. Sus dos obras póstumas están preñadas de ideas reformadoras y modernizadoras para España. En La Hacienda de España en 1872 (1873) aboga por la reordenación de la Hacienda y la reforma de las cárceles, y arremete contra los monopolios y los estancos; en Vindicación del siglo XIX (1873) reitera su defensa de todo lo que el siglo xIx, el siglo de la economia, ha supuesto para el progreso de las fuerzas económicas y sociales. Teniendo en cuenta que murió el 29 de septiembre de 1872, y que la escena política se preparaba para vivir, en los dos años siguientes, las convulsiones de la Primera República (desde el $11 \mathrm{de}$ febrero de 1873) y los inicios de una Restauración conservadora (desde el 31 de diciembre de 1874), su última reflexión no pudo resultar más oportuna y beligerante.

\section{LUIS MARÍA PASTOR COMO LIBRECAMBISTA}

Lo que por encima de todo define a Pastor es su defensa de la libertad económica. Aunque había leido a los clásicos, su autor predilecto será Frede-

is Pastor fue elegido presidente de la Asociación, pero sólo una vez que Alejandro Mon, a quicen se le habia ofrecido ed cargo con anterioridad, rehuso. Vease AA.VV. (1859), donde se cita tambien la lista completa de fundadores.

19 A este congreso asistieron tambien Figuerola, Carballo, Pesquera, Quijano y Marcoartu. El tema tue la reforma fiscal, y acudieron congresistas de Alemania, Francia, Suiza, Polonia, Rusia c Italia, con diferentes planteamientos $c$ ideologias. Una de las conclusiones del congreso fue que las aduanas, mientras subsistieran, deberian tener un caracter puramente fiscal. Este congreso supuso el descubrimiento de un joven de veintiseis años llamado Marie.Esprit-Léon Walras. Vease AA.VV. (1863b), p. 185, y Cabrillo 11991 ). 
ric Bastiat, y por eso sus escritos respiran un cierto aire de simplificación y divulgación. Con todo, su visión de la economia liberal tiene puntos de interés.

En su discurso de ingreso en la Real Academia de Ciencias Morales y Politicas, donde reemplazó a Bravo Murillo por enfermedad de éste, Pastor manifestará su convencimiento de que la Economía Política es una cosmovisión del mundo históricamente determinada. Dirá que esta ciencia «no pudo aparecer ni coexistir con la civilización oriental, ni con la civilización griega, ni con la civilización romana, ni con la civilización feudal» ${ }^{16}$. Sólo en el siglo xvin europeo se daban las condiciones para que el «derecho de la fuerza» fuese sustituido por la «fuerza del derecho» ${ }^{17}$. De alguna manera, Luis Maria Pastor se consideró a si mismo un sucesor de Álvaro Flórez Estrada (1765-1853), quien habia contribuido a difundir en España el pensamiento de Adam Smith y J. B. Say 18 . Para Pastor, la economía era una ciencia "perfectamente formulada» ${ }^{19}$ que "tiende a seguir los impulsos de la razón humana y a ensanchar y estrechar más cada vez las relaciones de los hombres entre sim ${ }^{20}$. La influencia de Bastiat le lleva a despreciar con excesiva rotundidad todas las tesis socialistas, sin embargo, la revisión critica que hace del pensamiento de Quesnay, Malthus y Ricardo resulta interesante. Asi, es capaz de señalar que la típica sobrevaloración de la agricultura en la escuela fisiocrática fue debida a que su trabajo era una reacción frente al atraso de este sector en Francia ${ }^{21}$; que el principio sobre la población de Malthus ha sido superado por el progreso de la civilización 22; o que las opiniones de Ricardo sobre la renta de la tierra carecen de base pues esta renta no puede ser excepción a las leyes generales de la economia ${ }^{23}$.

Pero donde Pastor carga las tintas es en la defensa del librecambio frente al proteccionismo. Supone que el mercantilismo y sus secuelas son un «funestisimo error» ${ }^{24}$, y no esconde su admiración por los políticos liberales (Peel, Chevalier, Cavour) ${ }^{25}$ que han sabido extender las ventajas del librecambio por el mundo entero. En su opinión, sólo Francia y España, por «la fuerza de los

\footnotetext{
16. AA.V. (1863a), p. 7.

17 Ibidem. p. 17.

i* Pastor (1868), p. 184.

14 Ibidem. P. 149

2"Ibidem, p. 249

21 Ibidem. pp. 117 y ss.

22 Ibidem. p. 168

23 Ibidem. cap. XIII.

24 Ibrdem. p. 153.

"Ihidem. p. 189.
} 
intereses monopolizadores», habian tendido a mantener «cerradas las puertas de la administración pública a las doctrinas económicas» 26.

El librecambismo de Pastor no admite concesiones, y por eso critica a List con la misma fuerza que a Cromwell o Colbert. No cree en la doctrina de «las restricciones son el medio y la libertad el fin» ${ }^{27}$. Sus argumentos, expresados en términos actuales, son dos: primero, la pérdida de valor que se produce al tener que consumir productos de peor calidad y mayor precio no suele verse compensada, porque la protección tiende a amparar el nacimiento de industrias sin futuro en un mundo competitivo; segundo, no es cierto que las em. presas nuevas estén en desventaja con respecto a las antiguas, sino que suele suceder todo lo contrario: la recién llegada puede aprovechar las ventajas tec. nológicas con menores costes e inercias que las empresas antiguas 28 .

Aunque Buenaventura Carlos Aribau (1798-1862), prohombre de la industria algodonera catalana, se considerase «amigo y compañero inseparable del autor [Luis Maria Pastor] desde la primera juventud» en el prólogo de La ciencia de la contribución (1856), las ideas que Pastor desarrolló en la década de 1860 tuvieron, a la fuerza, que enfrentarle con los ardientes defensores catalanes del proteccionismo à la List. El más activo de todos ellos, Juan Güell y Ferrer, se constituiria en un decidido adversario de Pastor desde que éste criticara el "feudalismo industrial» en el discurso de inauguración de la Asociación para la Reforma de los Aranceles ${ }^{29}$.

La confrontación de Güell con Pastor prosigue en Güell (1866), donde tras describir al ex ministro de Hacienda como "activo escritor», «incansable orador», «apóstol más ardiente de la escuela radical» e «ilustrado paisano» ${ }^{30}$, inicia un ataque despiadado a sus posiciones teóricas. En cualquier caso, Güell no cree que Pastor actúe en solitario, sino que, en última instancia, está representando los intereses de las clases sociales dominantes en la sociedad madrileña. Güell no se recata al decir que Madrid tiene una «vida artificial, sostenida por el presupuesto y la centralización», y añade:

los economistas radicales que esto han comprendido, desviandose de los principios cientificos, contrarios a las aduanas, han persuadido al gobierno, y en general a todas las clases que directa o indirectamente viven del presupuesto que la

26 Ibidem, p. 187.

27 lbidem, p. 228.

${ }^{2 k}$ Ihidem, pp. 230.232

29 Véase AA.VV. (1859, p. 15) y contestación en Güell (1861). En Güell (1863) este autor extiende su critica a los economistas de la Sociedad Libre de Economia Politica y a los del Ateneo madrileño.

"Güell (1866), p. 29. 
Hacienda no tiene otra salvación que las Aduanas, y que éstas no pueden producir sino con derechos arancelarios muy módicos, para que las grandes importaciones extranjeras den rendimiento fabuloso ${ }^{31}$.

Güell pretende haber desenmascarado, de este modo, a los que defienden el librecambio, y propone "descubrir las verdades» utilizando un método inductivo (cita a Bacon) basado en la experiencia histórica ${ }^{32}$. A su juicio, los errores de Smith, Bastiat y Say se ponian de manifiesto con el fracaso de la Italia liberal de Cavour (adrama desconsolador» ${ }^{33}$ ), «explotada por la Inglaterra, la Francia y otras naciones por medio de tratados de comercio que ocasionan una balanza contraria en sus cambios de productos» ${ }^{34}$. Es más, Güell llega a decir que «Inglaterra y Francia deben su prosperidad a las prohibiciones, a los derechos elevados, a las trabas, a las zonas» ${ }^{35}$, y más adelante que «los hombres de Estado de Inglaterra antes, después, ahora, y de seguro en lo sucesivo, varian su sistema económico según lo exigen las condiciones de cada época» ${ }^{36}$.

En la década de 1860, Güell y Pastor discutieron sus muy divergentes posiciones en los opúsculos y en la tribuna del Senado, pues ambos eran senadores regios, pero también intercambiaron una interesante correspondencia. En Güell (1869) se recogen cartas que insisten en los tópicos ya señalados, pero alguna es tan radical que llega a afirmar: «Todos los españoles, pues, vivimos de abusos, incluso los que se lamentan de ellos; y si asi viven y medran todas las clases, ¿no medra y prospera el pais? He aquí el objeto del sistema protec. tor" ${ }^{37}$.

Pero las ideas de Pastor no sólo encontraron oposición en los prohombres del proteccionismo, sino que también tuvo ocasión de escuchar fuertes críticas desde sectores más moderados, como por ejemplo el que representaba Juan Bravo Murillo. Siendo ambos senadores, el 6 de abril de 1865, protagonizaron una virulenta discusión sobre la verdadera importancia de la balanza de comercio ${ }^{38}$. Luis Maria Pastor, siguiendo de nuevo a Bastiat, se opuso a conside-

"Ibidem, p. 6. Como señala Tortella $(1994$, p. 167), la proposición «cuanto más protege un arancel menos ingreso producem, solo es cierta a partir del nivel de máxima recaudación.

"2 Güell (1866), p. 33

"lbidem, p. 62 .

it Ibidem. p. 97.

"Ibidem, p. 13

"Ibidem, p. 72

"C Carta de Juan Güell y Ferrer a Luis Maria Pastor, 12 de mayo de 1868, recogida en Güell (1869), p. 19

"Vease para lo que sigue el Diario de las sesiones de las Cortes. Senado, sesión del 6 de abril de 1865. 
rar que todo déficit en balanza comercial fuese negativo. Dijo: «importamos más que exportamos, luego la diferencia es un saldo en contra. Esto es una equivocación, que está desvanecida hace más de cuarenta años». En su opinión, el déficit no debía causar gran preocupación siempre que se obtuviera el suficiente crédito para financiarlo. Y para ello, resultaba indispensable abrirse a la libertad de comercio. Pastor también cuestionó la forma de contabilizar las relaciones económicas con el exterior, que en su tiempo se limitaban a la balanza comercial, por dejar de lado todas las operaciones que no estuvieran directamente relacionadas con la importación y la exportación de mercancías.

La reacción de Bravo Murillo parece fuera de tono. No sin cierta sorna, empezó diciendo que Pastor expresaba «su sueño dorado» al exponer sus ideas «con toda conciencia». Criticó las objeciones de Pastor al registro de la balanza de comercio por fútiles ${ }^{39}$, y terminó preguntándose por las consecuencias que acarrearía la libertad de comercio para España:

Una inundación, porque todo el que necesite un articulo cualquiera, sea quien quiera esa persona, aunque sea el presidente del Senado, resolviendo únicamente la cuestión individual, va, como es natural, a lo más barato; de suerte que todos se proveerán del género extranjero, que es mejor y más barato.

Como puede apreciarse, ni siquiera Bravo Murillo escapaba a la pobre retórica de la defensa del proteccionismo en España.

\section{LUIS MARÍA PASTOR COMO DEFENSOR DE LA LIBERTAD BANCARIA}

«Ha llegado también para nosotros el momento histórico del crédito», escribia el liberal Joaquín María Sanromá en el prólogo de la segunda edición de Filosofía del crédito (1858), la primera obra de Luis Maria Pastor dedicada explicitamente al crédito y la banca. En efecto, sólo dos años antes se habia promulgado la ley de bancos, de 28 de enero de 1856, verdadero punto de partida de la historia de la banca moderna en España. Por eso, las fuentes de inspiración de Pastor estarán, principalmente, en el mundo anglosajón, donde existia un sistema financiero más desarrollado. Cita expresamente a Smith, Col-

${ }^{34}$ En Bravo Murillo (1865, p. 193), comentando esta sesion, se llegará a escribir: « ¿se puede, ipor Dios santo!, explicar de este modo el exceso de la importación sobre la exportación que ofrece nuestra balanza?». 
quhoun, McCulloch, Carey, Coquelin, Parnell y Pebrer ${ }^{\text {t0 }}$. Esto puedo sorprender, pues es conocida la influencia ejercida por el Journal des Economistes en los iiberales españoles de la época. Pastor mismo cita a muchos de los escritores ingleses a traves de versiones francesas. Pero tampoco deben olvidarse las reticencias que Pastor siempre manifestó hacia la influencia de Francia en los asuntos españoles, que consideraba excesiva, y su repetida admiración por el modelo de desarrollo anglo-americano ${ }^{41}$.

Podríamos agrupar en tres las ideas principales que sustentan Filosofía del crédito. Una, muy clara, es su defensa del tipo de interés como justa y necesaria retribución del capital. Aunque no lo aduce, su reflexión parece directamente influida por el debate que provocó la ley del 14 de marzo de 1856 que eliminó la imposición de topes máximos sobre el tipo de interés. Pastor no duda en calificar de excesivos los tipos de interés aplicados en España ${ }^{+2}$, pero desestima la solución de ponerlos bajo el yugo de las leyes de la usura. En su opinión, sólo la extensión del crédito contribuirá efizcamente a rebajar los tipos de interés, y con tipos así reducidos se verán incrementados el desarrollo de la industria y la riqueza nacional ${ }^{43}$.

La segunda cuestion fundamental de Filosofía del crédito es el estudio del crédito público, es decir, de la capacidad del Estado para endeudarse y financiar ortodoxamente el déficit público. No duda en manifestar su estupor porque se hubiese extendido «con el nombre de renta lo que nuestros abuelos llamaron deuda» ${ }^{+4}$, queriendo ocultar de este modo la verdadera indole del contrato, es decir, la obligación de devolver el capital prestado. Una buena parte de la obra ${ }^{4}$ está dedicada a la evolución histórica de las deudas públicas francesa, inglesa y española, aunque su ideal será siempre el modelo de

4i) Pastor (1858), p. 61. Pebrer, que es el menos conocido, era un escritor liberal, de origen español pero que desarrolló su actividad en Inglaterra donde escribió una historia del Imperio bri. tánico (vease Grice-Hutchinson, M. (1982): «Las vicisitudes de un economista», en AA.VV: Homenaje a Lucas Belirán, Madrid: Editorial Moneda y Crédito). En el prólogo citado, Sanromá añade una larga lista de influencias: Augier, Avril, Bastiat, Baudrillart, Bentham, Bianchini, Cieszkow'ski, Courcelle-Sencuil, Coutois, Dufresne Saint-Lion, Fulda, Ganilh, Gilbart, Guer, Hearhfield, Hennet, Hufeland, Nebenius, Oı, Papion, Pinlo. Price, Rau, Ricardo, Riedel, Roscher, Rossi, Say, Schübler, Saden, Siuart Mill, Turgot y Welz. Los nombres se han ordenado alfabeticamente y aparecen en cursiva los citados alguna vez en J. A. Schumpeter (1971 [1954]).

+ Un ejemplo de ello puede ser el libro-homenaje a Richard Cobden que publico a su muerce, en 1865, la Asociación para la Reforma de Aranceles, a instancias de Pastor que era su presidente.

12 Pastor (1858), pp. 182.183.

\$ Ibidem. pp. 177 yss.

14 Ibidem. p. 146.

\$5 Ibidem, pp. 35-144. Mas tarde, Pastor (1863) le situaría como uno de los primeros historiadores de la Hacienda Pública española. 
Estados Unidos, «el pais más económico del mundo» ${ }^{46}$. Quizá lo más interesante de esta parte sean las valoraciones que hace Pastor, al final de la obra, sobre el importe alcanzado por la deuda y la mejor forma de afrontar su reestructuración. A la vista de un cuadro comparativo, que resume su investigación, nos dice que los 812,50 reales de deuda por habitante existentes no suponian una insoportable carga para los españoles ${ }^{47}$, pero que era preciso abaratar su coste financiero (la deuda española era la más cara de cuantas analiza), reordenarla en sólo dos o tres clases, procurar conservar el control nacional de la misma (prefiriendo la deuda interior sobre la exterior) y mejorar la identificación de sus titulares no emitiendo valores al portador ${ }^{48}$. Como se aprecia, son medidas de indole exclusivamente técnica y que eluden el problema de fondo, es decir, la reducción del déficit. Su mayor preocupación, en esta obra, parecía ser que el Estado mantuviese una correcta organización del servicio de la deuda para que su consideración como deudor no se viese mermada.

Finalmente, en Filosofía del crédito, Pastor quiere distinguir tres sistemas bancarios en el mundo: 1) el de Estados Unidos y Escocia; 2) el de Inglaterra; 3) el prevaleciente en el continente europeo ${ }^{\text {t9 }}$. El primero es, a su juicio, el más perfecto pues admite la libertad bancaria sin apenas restricciones. Tan sólo critica que en el caso escocés esté muy extendida la responsabilidad ilimitada de los socios, lo que podria dificultar la obtención del capital necesario para su desarrollo. El sistema inglés es menos perfecto aún, pues desde 1826 estaba explicitamente reconocido el monopolio de emisión del Banco de Inglaterra en un area de 65 millas en torno a Londres. Además, Pastor observa con preocupación que no se abonan intereses en la captación de depósitos y que prevalece, asimismo, la responsabilidad ilimitada. Pero donde Pastor carga sus tintas es contra el caso de la Europa continental, siempre proclive al otorgamiento de monopolios y a caer en lo que él llama «el error de Law" ${ }^{50}$ : es lo mismo crear billetes que moneda. Para Pastor, el uso del papel moneda terminará por imponerse, pero sólo estaremos a salvo de grandes perturbaciones si

th Pastor (1858), p. 152

4; Como referencia, y en base a las estimaciones disponibles, hemos calculado que la deuda publica en circulacion representaba, en ese momento, en torno a un preocupante 60 por 100 de la renta nacional. Veanse datos estadisticos en A. Carreras (coord.) (1989): Estadisticas históricas $d^{\circ}$ Iispana Siglos $x i x$ y $k$. Madrid, Fundacion Banco Fixterior.

is Pastor (1858), pp. 364-36i.

${ }^{49}$ Ibidem, pp. 201 y ss.

51" Ibidem, p. 40. "Error de Law" por John Law (1671-1729), economista escocés que llevo a cabo un primer y fallido experimento con billetes de banco en la Francia de Luis XV. 
se da al papel «una garantia incuestionable del mismo valor que se cede, tan real y efectiva como hoy acontence con los metales preciosos» 51.

Aunque muchas de sus ideas sobre el crédito privado están en germen en Filosofía del crédito, será en 1865, cuando publique La libertad de bancos y cola del de España, el momento en que, a mi juicio, Luis Maria Pastor empezará a destacar como autor de cierta originalidad y digno de atención en el panorama de la historia de las ideas monetarias en España. Sin embargo, estas mismas ideas no serán ajenas, en absoluto, a lo que una corriente de la ciencia económica había venido exponiendo desde hacia algunas décadas y que hoy conocemos como Free Banking School (FBS) ${ }^{52}$. Por esta razón, vamos a ir desgranando el pensamiento de Pastor en epígrafes acordes con la denominación que hoy reciben los postulados de la FBS. El objetivo será hacer perceptible que su análisis tuvo que verse influido por sus muchas lecturas de economía radicalmente liberal.

\section{La libertad en la emisión de billetes}

«El billete no es moneda», repite Pastor en La libertad de bancos $\$ 3$. El billete no tiene valor alguno propio y, por tanto, nunca puede tener curso obligatorio. Es tan sólo como un pagaré, una letra o una libranza. Nadie diria que se cancelan las obligaciones cuando se reciben billetes, pues siempre quedará pendiente la obligación del banco emisor de hacerlos efectivos. Es más, los billetes deberian ser «obligatorios civilmente», es decir, protestables y equiparables en todo a los demás efectos mercantiles 54 . Hoy, esta idea nos puede parecer extraña, pero se corresponde perfectamente con el pensamiento liberal de esa escuela de filósofos y modernos banqueros que fue la FBS. Además, en todos los paises ha existido una fase histórica, más o menos prolongada, donde se han impuesto los principios de libertad bancaria, cuya máxima expresión es

") Pastor (1858), p. 32.

"Sobre la Free Banking School empicza a existir una cierta literatura, gracias al impulso inicial de F. A von Hayek. Dos obras de amplio interes son White (1984), para un análisis de las doctrinas cconomicas, y Dowd (ed) (1992), que contiene un exhaustivo recuento de casos historicos de free banking. En España, contamos con los trabajos de Tortella (1973), Schwartz (1982), Garcia Ruiz (1988) y Sudria (1995) sobre esta cuestion.

s3 Pastor (1865), pp. 6 y ss.

\$4 En esta consideración, Pastor se apartara de Laureano Figucrola, que fue uno de los catorce firmantes de un informe contra la pretensión del marques de Santa Marta de hacer efectivos 50 billetes del Banco de España mediante un juicio ejecutivo. Véase AA.VV. (1866). 
la pretensión de arrancar de las manos del Estado el privilegio de la emisión de billetes.

Asi pues, para Pastor, lo primero es desvelar el misterio del billete. Un instrumento que surgió por «asentimiento espontáneo» y para «mutua y general conveniencia», pero que ha sido apropiado por el Estado para sus fines pretendidamente sociales ${ }^{5}$. El billete no es moneda, sólo «erróneamente ha dado en llamarse papel-moneda» ${ }^{56}$. La emisión de moneda sí puede dejarse en las manos exclusivas del Estado, la de billetes nunca. La razón:

Si en lugar de un solo banco existieran otro u otros, ejercerian, como sucede en Inglaterra, en los Estados Unidos, en Escocia, una vigilancia extrema unos sobre los otros, y el temor que esta vigilancia infundiria sería suficiente preservativo para que ninguno se expusiese a que su papel fuese desairado por la opinión 57 .

Pastor, sin saberlo, está invocando los principios de la «economia de la reputación» que tan buenos resultados está alcanzando hoy dia ${ }^{58}$. Principios que sólo pueden funcionar dejando actuar a los individuos en libertad. Una pluralidad de emisores de billetes parece ser la única manera de alcanzar el equilibrio en un mercado donde los productores de billetes gozan de muchos incentivos para excederse en sus atribuciones, dado el bajo coste de la tecnologia emisora.

\section{Las crisis monetarias}

Las crisis son siempre monetarias, viene a decir L. M. Pastor, y, desde luego,

las más importantes y trascendentales que han tenido lugar desde la existencia de los bancos de emisión, han sido TODAS OCURRIDAS EN BANCOS PRIVILEGIADOS [...] mientras que, por el contrario, Escocia, que es el único pueblo del mundo en que prevalece el principio de libertad, aunque algo limitado por las leyes de 1844 y 1845 , es también el único que se ha preservado de aquella calamidad ${ }^{59}$.

ss Ibidem, pp. 31 y ss.

so lbidem, p. 68.

57 Ibidem, p. 95.

sy Incluso ya se puede encontrar en manuales vanguardistas como el de $\mathrm{O}$. J. Blanchard y $\mathrm{S}$. Fischer (1989): Lectures on Macroeronomics, Cambridge (USA), The MIT Press, capítulo 11.

5y Pastor (1865), p. 56. El resalte en letra mayúscula es del propio autor. 
Su demostración, esta vez, se remite a la historia. La Francia de Law, la Inglaterra de principios del siglo XIX, Estados Unidos en 1837 y España en 1848 son ejemplos que cita para reforzar sus asertos ${ }^{60}$. Al final, el sistema de libertad bancaria imperante en Estados Unidos, «pais completamente democrático», le parece la situación más idónea. El contraejemplo es Francia, con «privilegio y monopolio en todas las instituciones económicas", y España, donde «hemos tenido la debilidad de convertirnos en sumisos y humildes imitadores de los métodos franceses» "1. En su opinión, la legislación del Banco de España ha sido contraria a las buenas doctrinas y encaminada a convertir el establecimiento «de una institución de crédito en una oficina del gobiernom, siguiendo el modelo francés "2. Para Pastor ésta era la causa de que, de cuando en cuando, se apareciese al Banco de España el «cometa de la cola» 63. Pastor se referia asi a la larga cola de gente esperando a convertir sus billetes en metálico, que resultaba caracteristica cada vez que el Banco de España tenia alguna dificultad. En este caso, y en todos, el motivo de la crisis era siempre el mismo: «la moneda que salia del Banco para ser entregada al gobierno y para operaciones aventuradas [y que] no vuelve a sus cuevas» ${ }^{64}$. Además, al estar asegurados los bancos emisores contra todo peligro, por su privilegio, «han de vivir siempre a pesar de sus errores» ${ }^{65}$. Pastor no reprime sus impulsos a la hora de criticar esta recurrente situación.

\section{Las doctrinas de la Banking School}

Tres principios teóricos fueron desarrollados por la llamada Escuela Bancaria (Banking School) (BS), que también compartió la FBS: la doctrina de las letras reales, la doctrina de las necesidades del comercio y la ley del reflujo ${ }^{\text {tot. }}$. Veremos, a continuación, como Luis Maria Pastor mostró su total conformidad con la exacta aplicación de estas teorias, siendo el único autor español que, al parecer, entendió la importancia de una polémica que centró el interés del pensamiento monetario británico en la primera mitad del siglo XIX.

(6) Ibidem, cap. III.

"I Ibidem, p. 55

(2 Ibidem, p. 72

(1) Ibidem, p. 74

it Ibidem, p. 62

4 Ibidem, p. 65.

to Véasc White (1984), p. 135. En esta obra se contiene una magnífica presentación de las doctrinas de la Banking School que vamos a examinar. 


\section{3a. La doctrina de las letras reales}

Dentro de la controversia «bullonistas», desatada a raiz de la suspension temporal de los pagos en oro por parte del Banco de Inglaterra, desde finales del siglo Xvill, surgirán frente a los defensores del retorno inmediato a la convertibilidad de los billetes en bullion (= oro o plata en barras), aquellos otros que se agruparán bajo la denominación de «escuela antibullonista», «escuela antimonetarista» o «escuela de las letras reales». ¿Qué defendian estos autores? Pues, simplemente, que no habia peligro de sobreemisión si los billetes en circulación respondian al descuento de efectos comerciales a corto plazo que fuesen genuinos y solventes, es decir, «letras reales». Por lo tanto, no existiria una necesidad imperiosa de volver al patrón oro aun cuando este fuera un objetivo no desdeñable a medio plazo. La opinión de Pastor no puede ser más coincidente con la de esta escuela:

Mientras los billetes no representen mas, como debe suceder, que operaciones mercantiles de corto vencimiento 190 dias es el maximum que establecen todos los estatutos) son buscados y apreciados, porque viniendo el banco a cen tralizar en sus cajas toda la circulación de la plaza, se establece un movimiento de rotación por el cual todo el papel del banco tiene que volver a sus cajas en el máximum del periodo de los 90 dias, equilibrándose, casi diariamente, la entrada con la salida ${ }^{67}$.

\section{3b. La doctrina de las necesidades del comercio}

Ligada a la anterior se formuló la «doctrina de las necesidades del comercio», la cual sugiere que las transacciones regulan la demanda de dinero, por lo que la cantidad de dinero en la economia vendrá «gobernada» por las necesidades del comercio. A este respecto, Pastor ${ }^{68}$ dice textualmente: «la verdadera garantia de la emisión, su límite legitimo, deben ser las necesidades justas y fundadas del comercio». Y, más tarde ${ }^{69}$, criticando la Bank Act británica de 1844, añade: «la circulación no puede ser una cantidad fija y constante».

\footnotetext{
hi Pastor (1865), p. 58.

or Pastor (1858), p. 192.

s9 Pastor (1865), pp. 104-105.
} 


\section{3c. La ley del reflujo}

Este postulado va unido indefectiblemente a los dos anteriores. Dado un nivel de transacciones en la economia, se precisa una cantidad de dinero determinada, y toda cantidad por encima de ésta, que no se necesite, volverá al banco. Los abullonistas» sólo podian admitir que esto ocurriria en caso de convertibilidad, aunque era un proceso lento y que tenía lugar a través de la balanza de pagos y no del sistema financiero. Por otro lado, partidarios de la BS y de la FBS coincidian plenamente en los principios anteriores, pero en la aplicación práctica de éstos era mucho más optimista la FBS, ya que creia que el proceso sería instantáneo y ocurriria por la devolución inmediata de los préstamos no utilizados. Pastor no parece prestar mucha atención a esta cuestión, e incluso en algún pasaje da la impresion de que se alinea con la postura «bullonista», al afirmar que la circulación «artificial» de billetes podria tener consecuencias inflacionistas ${ }^{70}$. Sin embargo, en el conjunto de su obra se respira una gran confianza en que los bancos y el público actuarán racionalmente, por lo que no podemos ser categóricos en este punto. Su insistencia una y otra vez recae sobre los puntos que le aproximan a la FBS y que Pastor resume en tres: $1^{\circ}$. Que la intervención del gobierno, lejos de ser una garantía para impedir la emisión inconsiderada de los billetes, constituye un verdadero peligro de que aquel mal se verifique; $2^{\circ}$. Que la principal y verdadera precaución debe ser que los bancos no entreguen sus billetes sino en equivalencia de valores realizables dentro del plazo de 90 dias a lo más; y $3^{\circ}$. Que la libertad y la competencia, que es su consecuencia, es el medio más eficaz para contener la emisión dentro de sus verdaderos y naturales limites ${ }^{71}$.

\section{LUIS MARIA PASTOR COMO REFORMADOR DE LA HACIENDA}

Para Luis Maria Pastor el problema de la Hacienda en España era inseparable de la necesidad de afrontar la instauración de un sistema impositivo moderno. Sus propuestas más ambiciosas sobre esta materia se contienen en La ciencia de la contribución (1856). No en vano, el autor manifiesta en el prólogo que no se atrevió a publicar la obra con anterioridad, dado el «temor de las contrariedades sin cuento a que había de verse expuesta la nueva teoría que

70 Ibidem, p. 127.

1 Ibidem, p. 99. 
arrojaba a la arena de la discusión» ${ }^{72}$. Su reciente paso por el Ministerio de Hacienda complicaba aún más las cosas ("habrá, por esta causa, quien desee poner en contradicción al escritor con el ministro, o al ministro con el filosofo» ${ }^{73}$ ), pero Pastor se decidió a publicarla sin recatar en lo más minimo su opinión personalisima. Su punto de partida serán los economistas clásicos (Smith, Say, Ricardo y Stuart Mill), aunque esta vez le servirán de fuente de inspira. ción pero también de objeto de critica. De hecho, en el libro no sólo se argumenta contra el sistema impositivo español, sino también contra el prevaleciente en toda Europa ${ }^{74}$.

Pastor se muestra de acuerdo con las apreciaciones de los clásicos sobre que los impuestos deben ser cantidades ciertas y no arbitrarias, y en que han de ser moderados y se debe evitar que afecten a la producción. Sin embargo, propone un principio nuevo, aunque inspirado en Bastiat, cuya obra Las armonías económicas habia sido traducida al castellano en 1853 75. «El hombre está obligado a contribuir a las cargas de la sociedad de que forma parte, con proporción a la clase o jerarquia que en ella ocupa y a las ventajas que de la misma reporta» 76 . De acuerdo con esta idea, Pastor critica abiertamente el sistema fiscal español, «asentado sobre las mismas bases que el que teniamos dos siglos ha" " 7 . La descripción que hace de los métodos empleados en su recaudación es aterradora ${ }^{78}$. En opinión de Pastor, el sistema está completamente anticuado, es incapaz de obtener una recaudación suficiente y obliga a em. plear una enorme masa de funcionarios (20.000 calcula Pastor) ${ }^{79}$. En contraposición al sistema vigente, Pastor propone una contribución única y general, es decir, recuperar la iniciativa de su admirado Martín de Garay en $1817^{80}$, que empezaba a introducirse en algunos paises desarrollados. Pero Pastor pretende mejorar el planteamiento, y se opone al «error de los economistas» que hace gravitar la carga fiscal sobre los «productos netos» de cada persona ${ }^{81}$. « $¿$ Podrá ser justo, conveniente, ni aun equitativo - se pregunta Pastor - que el que es laborioso pague doble contribución que el holgazán?» ${ }^{82}$. Solución: establecer

${ }^{12}$ Pastor (1856), p. XXIX.

73 Ibidem, p. XXXII.

is Ibidem pp. 259-260.

is Vease Bastiat, F. (1850; 1853): Las armonias económicas, Madrid, Imprenta de D." Francisca Pérez Romero.

in Pastor (1856), vol. II, pp. 2 y3.

7 lbidem, vol. I, p. 245.

is Ibidem, vol. II, p. 85 .

is Ibidem, vol. II, p. 96.

Rul Ibidem, vol. II, p. 110.

${ }^{81}$ Ibidem, vol. II, p. 207

$\$ 2$ Ibidem, vol. I, p. 210 . 
una contribución única por cada clase de personas, en función de su participación en los bienes de la sociedad, y repartirla por igual entre todos los miem. bros de cada clase.

Las ideas de Pastor sobre Hacienda no han gozado en España de mucha consideración, y se le ha acusado de ser poco relevante, poco «cientifico»y desconocer las realidades económicas y administrativas ${ }^{83}$. Sin embargo, el historiador norteamericano de la Hacienda E. R. A. Seligman le calificó como el «principal de los antiguos escritores de Hacienda» en España ${ }^{84}$, no inferior a José Piernas Hurtado que, sin embargo, será el único finalmente reivindicado en España para ese periodo ${ }^{85}$. Pero incluso Seligman parece no entender adecuadamente a Pastor, pues, como le critica su traductor al castellano, Lorenzo Victor Paret, en realidad Pastor no defiende un impuesto proporcional, como dice Seligman, sino una «capitación graduada» ${ }^{86}$. En mi opinión, lo que apunta Pastor no es sino una anticipación de lo que hoy dia constituye uno de los caballos de batalla de la reforma fiscal: el impuesto de tarifa uniforme (flat tax). Con un impuesto de este tipo se evitarian algunas de las distorsiones y malas asignaciones que favorecen los sistemas tributarios vigentes, pero se reduciria en mucho la progresividad del impuesto y los efectos redistributivos del sistema. Lo que es indudable es que este impuesto simplificaria enormemente la recaudación, uno de los principales objetivos de la propuesta de Pastor.

Tras la revolución de 1868 , Pastor creerá que ha llegado su momento, y poco antes de morir dejará escrito que

todas las naciones bien administradas cuentan con esa contribución general. Francia y Bélgica tienen la personal y la de la riqueza mobiliaria, Inglaterra el Income Tax, y en España es más indispensable aún, porque la reclama la indole democrática de las instituciones ${ }^{87}$.

La orientación reformadora del llamado «sexenio revolucionario» (1868-1874) parecerá darle la razón con la supresión de las contribuciones indirectas y la introducción del impuesto sobre sueldos y asignaciones ${ }^{88}$, pero, a continuación, las actuaciones de la Restauración tratarän de frenar la modernización del sistema fiscal español.

s3 Véase Calle (1978), pp. 312.313

k4 Seligman (1913 [1894]), p. 212.

*5 Beltran (1989), p. 384.

*6 Véase el apéndice de L. V. Paret a Seligman (1913 [1894]), p. 414.

8: Pastor (1873), p. 287.

** Véase Comin (1988), vol. I, pp. 321 y ss 


\section{LUIS MARIAA PASTOR: \\ UN ECONOMISTA EN LA ESPAÑA DE ISABEL II}

La España de Narváez basó su sistema de dominación en un tipo de Estado centralizado, débil por falta de recursos, pero claro en sus propósitos de control y represión ${ }^{89}$. La influencia de los doctrinarios conservadores franceses (Royer-Collard, Cousin, Guizot) fue muy importante ${ }^{90}, y$ todo ello configuró un marco institucional poco favorable al desarrollo de un verdadero impulso renovador y modernizador. Como se ha señalado, la burguesía isabelina, globalmente considerada, fue poco dinámica, no siendo capaz de impulsar la misión histórica que su tiempo le otorgaba ${ }^{91}$. Con todo, no cabe pensar que la llamada "década moderada» (1844-1854) fuese un periodo homogéneo. La presencia de fuertes tensiones entre las distintas fracciones de la clase política se pone de manifiesto por la continua formación de nuevos gobiernos; juna docena! Existian fuertes divergencias en torno al papel de la monarquía, las relaciones con la Iglesia y la extensión de las libertades civiles. También se vertieron graves acusaciones de corrupción, sobre todo contra José Salamanca y las concesiones de ferrocarriles. Sin embargo, el debate propiamente económico fue muy pobre.

Pastor se inclinó por apoyar la fracción «puritana» del Partido Moderado desde 1847, año en que su lider, Joaquín Francisco Pacheco, logró formar gobierno durante casi seis meses. Sólo las turbulencias de la época permiten explicar que Pastor fuese ministro de Hacienda en el gabinete del conservador general Lersundi, aunque no olvidemos que se trataba de un gobierno de conciliación nacional. Un año después terminaría respaldando a O'Donnell y lo que de revulsivo tenia el pronunciamiento militar de la Vicalvarada. En las últimas páginas de la segunda edición de Filosofía del crédito (1858), Pastor manifestarà su esperanza en la prosperidad de Espana: «Se ha lanzado, aunque tarde, con gran fe, hacia las mejoras [de] la moderna civilización” ${ }^{92}$.

Pero pronto O'Donnell dio muestras de su moderantismo (p.ej. restable. ciendo la Constitución de 1845 con pocas modificaciones), la reina Isabel II siguió mostrando su condescendencia con Narváez y los cinco años de mandato de la Unión Liberal ( 30 de junio de 1858 - 27 de febrero de 1863) destacaron por sus múltiples contradicciones ${ }^{43}$. Cuando Pastor publica, en 1863, un

\footnotetext{
${ }^{84}$ Elorza (1992), p. XXIX.

"Vease Diez del Corral (1984).

"1 Canovas (1982), p. 261.

92 Pastor (1858), pp. 366-367.

"Vease, por ejemplo, Artola (1973).
} 
opísculo titulado Las elecciones, donde da cuenta del alto número de protestas electorales y de la baja representatividad del sistema ${ }^{94}$, esta sintonizando con la creciente frustración de muchos progresistas ante el desarrollo de los acontecimientos. Después de la dimisión de O'Donnell, se sucedieron los gobiernos conservadores, a la vez que la reina no supo colocarse por encima de los intereses de los partidos y, al condenar al ostracismo al partido progresista, empujó a éste hacia las posiciones del partido demócrata. Era el preludio de los acuerdos de Ostende (1866) y de la revolución de 1868.

Se ha dicho que la lucha de Pastor por el ideal de la libertad económica estuvo unida a su lucha por la instauración de la democracia en España ${ }^{45}$. Sin embargo, el aiejamiento de Pastor del moderantismo fue gradual. Prueba de ello es la distancia que Pastor quiso imponer, durante la celebración del curso 1862-63 en el Ateneo madrileño, entre sus posiciones y las del joven y fogoso demócrata Emilio Castelar ${ }^{96}$. A juicio de Pastor se podía separar la libertad económica de la libertad política, como hicieron en Gran Bretaña los librecambistas de Cobden frente a los cartistas de O'Connor, y, en su opinión, era preferible defender, en primer lugar, la libertad económica.

En cualquier caso, y a mi entender, la expectación con que Pastor terminaría por esperar la revolución de 1868 le aleja mucho de ese grupo con intereses particulares que, para algunos autores, fue el verdadero motor de la misma. Asi, se ha señalado, que la «pseudorrevolución» de 1868 fue en realidad un golpe de estado para poner remedio a los problemas angustiosos de un grupo de políticos ligados al mundo de los negocios que sufrian los efectos de una grave crisis económica ${ }^{47}$. No hubo revolución, como no hubo restauración, ya que revolucionarios de 1868 y restauradores de 1874 se sentaban juntos en los consejos de administración de las mismas compañias y tenian unos intereses comunes ${ }^{98}$. El estudio de la figura de Luis Maria Pastor podria ayudarnos a entender que junto a esos intereses tan concretos y explícitos, que sin duda existieron, latía un afán renovador que conectaba con una necesidad sentida de forma más general. Más bien parece que la revolución de 1868 se vio apoyada por amplios sectores del Ejército, por la mayor parte de los partidos politicos y por la gran mayoria de la población, y su politica económica tuvo como

44 Según los datos de Pastor (1863, p. 23), en el periodo 1846-1858 se registran, en media, un 27 por $100 \mathrm{de}$ actas impugnadas. Pastor propondra reformar el sistema electoral siguiendo las recomendaciones de John Stuart Mill en Considerations on Representative Government (1861).

95 Rodriguez (1873), p. 206.

* Veasc el prólogo de Pastor a AA.VV. (1863b).

97 Fontana (1973), p. 140.

9k Ibidem, p. 141 
objetivo el laissez-faire ${ }^{9 y}$. Por otra parte, este estudio vendría a confirmar la tesis expuesta ${ }^{100}$ de que existe una cierta asimetria entre el comportamiento de los librecambistas y los proteccionistas decimonónicos, pues mientras éstos defendian intereses empresariales muy concretos, en los otros destacaba la componente profesoral y teórica.

\section{BIBLIOGRAFÍA}

\section{PRINCIPALES OBRAS DE LUIS MARÍA PASTOR}

\subsection{Libros}

(1850), Filosofía del crédito, $1^{\text {a }}$ edición, Madrid, Imprenta de D. W. Ayguals de Izco.

(1856), La ciencia de la contribución, 2 vols., Madrid, Carlos Bailly-Bailliere.

(1858), Filosofía del crédito, 2d edición, Madrid, Carlos Bailly-Bailliere.

(1863), Historia de la deuda pública de España, Madrid, Imprenta de B. Carranza.

(1865), Libertad de bancos y cola del de España, Madrid, Imprenta de B. Carranza.

(1868), Lecciones de economía política, Madrid, Imprenta de la Gaceta Economista y Enrique Pastor Bedoya.

\subsection{Opúsculos}

La Bolsa y el crédito (1848), La Europa en 1860(1861), La política que expira y la politica que nace (1861), Las elecciones (1863), La politica que naci y la política que expira (1871). Vindicación del siglo $x i x$ (1873), La Hacienda de España en 1872 (1873).

\section{BIBLIOGRAFIA CITADA}

AA.VV. (1859): Asociación para la Reforma de los Aranceles de Aduanas. Noticia de su origen y planteamiento, acta de la sesión inaugural y juicio formado por la prensa, Madrid: Imprenta de la España Mercantil, a cargo de J. Moreno.

AA.VV. (1863a): Discursos pronunciados en la Real Academia de Ciencias Morales y Políticas con motivo de la recepción pública del Excmo. Sr. D. Luis María Pastor en 14 de junio de 1863, Madrid: Imprenta de Manuel Galiano.

AA.VV. (1863b): Conferencias librecambistas. Discursos pronunciados en el Ateneo cientifico $y$ literario de Madrid por varios individuos de la Asociación para la reforma de los aranceles de aduanas en el curso de 1862 a 1863. Madrid, Imprenta de Manuel Galiano.

${ }_{99}$ Tortella (1973), pp. 293 y ss.

${ }^{\prime \prime \prime}$ Cabrillo (1991), p. XI.II. 
AA.VV. (1866): Cambio de billetes del Banco de España. Informe que acerca de esta cuestión emiten los abogados, Madrid, Imprenta y Estereotipia de M. Rivadeneyra.

ANfs, R. (1988): «Economia y pensamiento económico en España», en M. Artola (dir.): Enciclopedia de Historia de España, Vol. 3, Madrid, Alianza Editorial, pp. 213-271.

ARTOLA, M. (1973): La burguesia revolucionaria (1808-1869), Madrid, Alianza/Alfaguara. (1978): «La acción del Estadom, en M. Artola (Dir.): Los ferrocarriles en España, 1844 1943, Vol. I, Madrid, Banco de España, pp. 341-454.

Bhltran, L. (1989): Historia de las doctrinas económicas, Barcelona: Editorial Teide.

Bravo Murilio, J. (1865): El pasado, el presente y el porvenir de la Hacienda Pública, Ma. drid, S. Martin y Jubera.

CABrillo, F. (1991): «El pensamiento económico de Laureano Figuerola», estudio preliminar a L. Figuerola: Escritos económicos, Madrid, Instituto de Estudios Fiscales y Ministerio de Economia y Hacienda.

CAl1.E, R. (1978): La Hacienda Pública en Espana. Un análisis de la literatura financiera, Madrid, Servicio de Publicaciones de la Fundación Universitaria San Pablo (CEU).

Canovas, F. (1982): El Partido Moderado, Madrid, Centro de Estudios Constitucionales.

Consw, F. (1988): Hacienda y economia en la España contemporánea, 2 vols., Madrid, Instituto de Estudios Fiscales.

Diez. dei. Corrai., L. (1984): El liberalismo doctrinario, Madrid, Centro de Estudios Constitucionales.

Down, K. (ed.) (1992): The Experience of Free Banking, Londres, Routledge.

ElorzA, A. (1992): "Estudio preliminar» a J. Antón y M. Caminal: Pensamiento político en la España contemporánea (1800-1950), Barcelona, Teide.

Estapr., F. (1961): «José Canga Argüelles y el pensamiento económico liberal español», prólogo a la reimpresión de Canga Argüelles, J. (1825): Los elementos de la ciencia de Hacienda, Madrid, Instituto de Estudios Fiscales.

Fontana, J. (1973): «Cambio económico y crisis política. Reflexiones sobre las causas de la revolución de 1868m, en Fontana, J.: Cambio económico y actitudes políticas en la España del siglo XIX, Barcelona: Ariel, pp. 97.146.

Garcia Rutz, J. L. (1988): “En torno a la libertad de emisión de billetes en España, 1856-1874", Ponencia presentada al III Seminario de Historia Económica Cuantitativa, Alcalá de Henares, Madrid.

GUELL. Y FERRER, J. (1861): Refutación de los discursos pronunciados por Excmo. Sr. D. Luis Maria Pastor y otros oradores en varias sesiones de la Asociación para la Reforma de Aranceles, Barcelona, Establecimiento Tipográfico de Narciso Ramirez.

- (1863): Observaciones a la reforma arancelaria cjecutada y a la propuesta a las Cortes por el Excmo. Sr. ministro de Hacienda, D. Pedro Salaverria, precedida de una reseña bistónicoeconómica de los reinados de las tres isabeles, primera y segunda de España e Isabel de In glaterra, Barcelona, Tipografia de Narciso Ramirez y Rialp.

- (1866): Causas económico-administrativas de los males actuales de España distintas de las que expone el Círculo de la Unión Mercantil de Madrid y justificación de la balanza de comercio, Barcelona: Establecimiento tipográfico de Narciso Ramirez y Cia.

- (1869): Polémica sobre cuestiones económicas entre D. Luis María Pastor y D. Juan Güell y Ferrer, publicadas por el viltimo, Barcelona.

Robrtguez, G. (1873): «Necrológica de Luis Maria Pastor» que precede a L. M. Pastor: La Hacienda de España en 1872, Londres: Establecimiento literario y tipográfico his. pano-americano de «El Eco de Ambos Mundos», propiedad de L. de Loma y Co- 
rradi \& Co. Editores. \Reproducido en Revista de Economía Política, 1973, N. 63, Documento 2, pp. 197.300.]

SANTHLLAN, R. 11982 [1865]): Memoria histórica sobre los bancos, Madrid, Talleres Tipograficos del Banco de España.

Schlмpғtlk, J. A. (1971 [1954]): Historia del análisis éconómico, Barcelona, Ediciones Ariel.

SChiwartz, P. (1982): «El monopolio del banco central en la historia del pensamiento económico: un siglo de miopia en Inglaterra", en AA.VV: Homenaje a Lucas Beltrán, Madrid, Editorial Moneda y Credito, pp. 689-729.

Sfligman, E. R. A. (1913 [1894]): El impuesto progresivo en la teoria y en la práctica, Madrid, Libreria General de Victoriano Suárez.

SLDRIA, C. (1995): «Los bancos de emisión provinciales en la España del siglo XIX», en P. Tedde y C. Marichal (Coords.), La formación de los bancos cenirales en España y América Latina (siglos $x I x$ y xx), Vol. I, Madrid, Banco de España, pp. 81-107.

Torrente Fortuxio, J. A. (1969): Salamanca, bolsista romántico, Madrid, Taurus.

TоктLl..A, G. (1973): Los origenes del capitalismo en España, Madrid, T'ecnos.

- (1994): El desarrollo de la España contemporánea. Historia económica de los siglos xIX y xx, Madrid, Alianza.

WHITE, L. H. (1984): Free Banking in Britain: Theory, Experience and Debate, 1800-1845, Cambridge, Cambridge University Press.

Zumalacarkeciti, L. (1952): El Banco de Isabel ll y la crisis de la banca de emisión española de 1847, Madrid, Gráficas Reunidas. 